\title{
INTRODUKSI HIGH POWER LED PADA PERIKANAN BAGAN TANCAP
}

\author{
INTRODUCTION HIGH POWER LED ON FISHERIES LIFT NET \\ Septian Eka Satriawan ${ }^{1}$, Gondo Puspito ${ }^{2}$, Roza Yusfiandayani ${ }^{2}$ \\ ${ }^{1}$ Program Studi Pemanfaatan Sumberdaya Perikanan, Sekolah Pascasarjana \\ ${ }^{2}$ Departemen Pemanfaatan Sumberdaya Perikanan \\ Fakultas Perikanan dan Ilmu Kelautan, Institut Pertanian Bogor \\ Korespondensi: Septiansatriawan@gmail.com,gondopuspito@gmail.com,ochaipb@gmail.com
}

\begin{abstract}
The use of TL lamp (tubular lamp) as a tool for collecting fish on the lift net has the lacks namely the light-emission which is too distributed widely and the high price of fuel. The use of HPL lamp (high power led) as energy efficient lamp is expected to substitute TL lamp to solve the issue. The aim of this study is to prove the use of HPL lamp on lift net is able to produce species composition and weight of the catch higher than TL lamp. The tests used two lift net, each of it used HPL lamp with silver plate cone as its reflector and TL lamp with zinc paper as its reflector. The results showed that the HPL lamp $90^{\circ}$ generated light distribution area with $120^{\circ}$ while TL lamp was up to $300^{\circ}$ with the highest value of each illumination 1,358 lux $\left(180^{\circ}\right)$ and $299 \operatorname{lux}\left(50^{\circ}\right)$. Composition of species and weight of the catch lift net which use HPL lamps $90^{\circ}$ produced 14 species organisms with the number of total weight $97.363 \mathrm{~g}(78.39 \%)$, higher than the TL lamp which produced 9 species organisms with the number of total weight $26.829 \mathrm{~g}(21.61 \%)$.
\end{abstract}

Keyword: HPL lamp, lift net, organisms, TL lamp

\begin{abstract}
ABSTRAK
Penggunaan lampu TL (tubular lamp) sebagai alat bantu untuk mengumpulkan ikan pada bagan tancap memiliki kekurangan yaitu pancaran cahaya yang terlalu menyebar dan mahalnya harga bahan bakar. Penggunaan lampu HPL (bigh power led) sebagai lampu hemat energi diharapkan mampu mensubtitusi lampu TL untuk mengatasi masalah tersebut. Tujuan penelitian ini adalah membuktikan penggunaan lampu HPL pada bagan tancap mampu menghasilkan komposisi jenis dan berat hasil tangkapan lebih tinggi dibandingkan dengan lampu TL. Pengujian menggunakan dua bagan tancap, masing-masing menggunakan lampu HPL dengan tudung bereflektor kertas perak dan lampu TL dengan tudung seng. Hasilnya menunjukan bahwa lampu HPL $90^{\circ}$ menghasilkan area sebaran cahaya sebesar $120^{\circ}$ sedangkan lampu TL mencapai $300^{\circ}$ dengan nilai iluminasi tertinggi masing-masing 1.358 lux $\left(180^{\circ}\right)$ dan 299 lux $\left(50^{\circ}\right)$. Komposisi jenis dan berat hasil tangkapan bagan tancap dengan menggunakan lampu HPL menghasilkan 14 jenis organisme dengan berat total $97.363 \mathrm{~g}(78.39 \%$ ), lebih tinggi dibandingkan dengan lampu TL yang menghasilkan 9 jenis organisme dengan berat $26.829 \mathrm{~g}(21.61 \%)$.
\end{abstract}

Kata kunci: bagan tancap, lampu HPL, lampu TL, organisme

\section{PENDAHULUAN}

Bagan tancap merupakan alat tangkap yang dioperasikan pada malam hari untuk menangkap ikan jenis teri dan udang rebon. Penggunaan cahaya lampu diperlukan untuk menarik ikan-ikan tersebut dibutuhkan. Fungsinya sebagai pemikat jenis ikan pemakan plankton atau plankton feeder agar berkumpul di bawah bagan. Salah satu faktor keberhasilan pengoperasian bagan tancap tergantung pada jenis lampu yang digunakan.

Jenis lampu yang digunakan oleh nelayan bagan sangat beragam seiring dengan perkembangan jaman. Awalnya nelayan menggunakan petromaks sebagai sumber cahaya, kemudian beralih ke lampu pijar, selanjutnya lampu merkuri dan lampu neon atau lampu TL. Saat ini kebanyakan nelayan menggunakan lampu TL. Beberapa kelebihan lampu TL, menurut Mahayati (2004), yaitu mudah dioperasikan, cahayanya sangat terang dan iluminasi cahaya yang dihasilkan relatif konstan. Adapun kelemahannya adalah cahaya yang dipancarkan mengarah kesamping, sehingga keberadaan ikan pemakan plankton tidak terpusat di bawah lampu, melainkan menyebar di sekeliling bagan (Ahmad 2014). 
Ini mengakibatkan hasil tangkapan bagan menjadi tidak maksimal.

Kelemahan lampu TL disiasati oleh nelayan dengan cara memasangkan tudung berupa ember plastik ataupun panci. Tujuannya agar pancaran cahaya mengarah ke bawah bagan. Hasil pancaran tersebut akan menyerupai suatu kolom silinder dengan diameteryang sangat sempit sehingga mengakibatkan jenis-jenis ikan yang menjadi tujuan penangkapan cenderung berkumpul pada kolom tersebut. Namun demikian, ada kelemahan utama lainnya, yaitu biaya operasional lampu TL sangat mahal. Hal ini dikarenakan pemerintah telah mencabut subsidi bahan bakar bensin dan solar untuk menghidupkan generator. Akibatnya, nelayan sering mengalami kerugian karena harga jual ikan jauh lebih rendah dibandingkan dengan harga bahan bakar.

Salah satu upaya yang dapat dilakukan untuk mengatasi permasalahan tersebut adalah mengganti penggunaan lampu TL dengan lampu lain yang lebih terang dan hemat energi seperti LED. Puspito et al. (2015) melaporkan penggunaan lampu LED DIP (dual in-line package) pada bagan tancap menghasilkan hasil tangkapan ikan yang lebih tinggi dibandingkan dengan lampu TL. Namun demikian, terdapat beberapa kelemahan yang ditemukan pada lampu tersebut diantaranya cahaya yang dihasilkannya masih kurang terang, perakitan LED cukup sulit dilakukan dan sudut pancaran cahayanya relatif sempit.

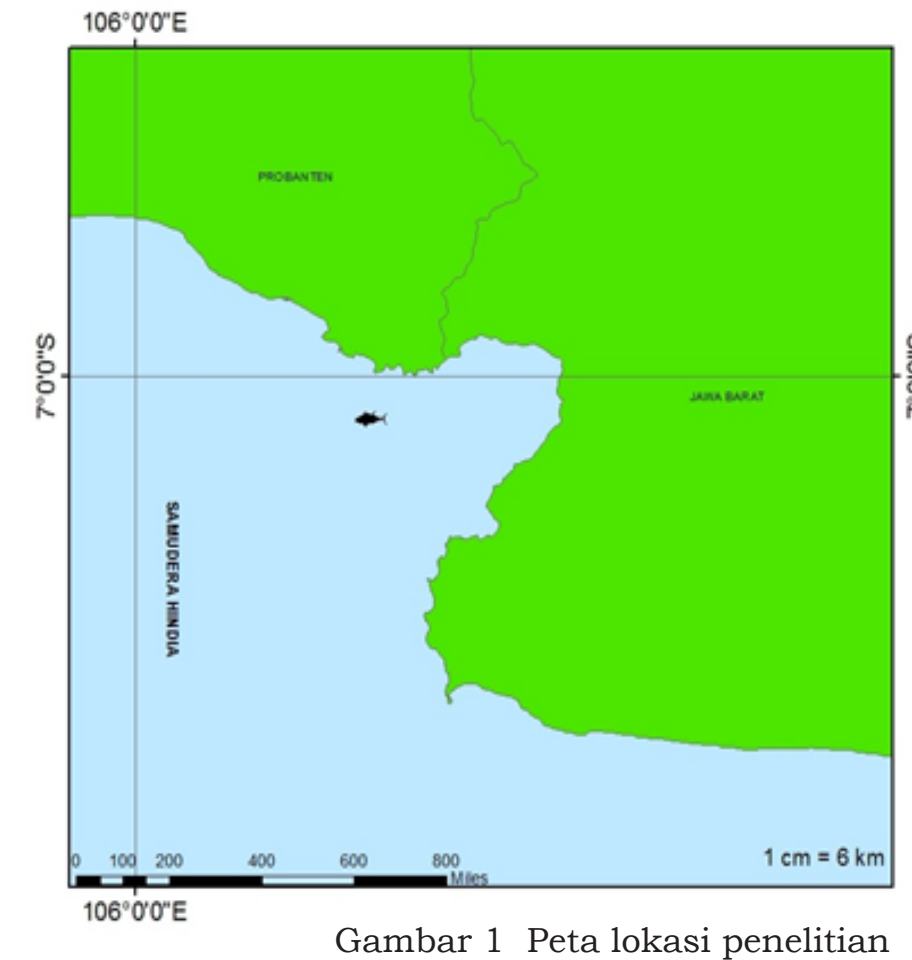

Gambar 1 Peta lokasi penelitian
Jenis lampu LED jenis HPL diperkirakan mampu memperbaiki kekurangan lampu LED DIP. Penyebabnya adalah cahaya yang dihasilkan lebih terang, waktu pakai lebih lama (hingga 100.000 jam), tegangan DC lebih rendah, tidak mudah pecah, sudut pancaran cahayanya lebih lebar, mudah dirangkai, sumber tenaga kecil (baterai $12 \mathrm{~V}$ ), dan ukuran lampu kecil sehingga sangat praktis digunakan. Lampu LED jenis HPL yang dirancang pada penelitian ini dilengkapi dengan reflektor yang dapat diatur sudut pancarannya. Tujuan penelitian ini adalah membuktikan bahwa komposisi jenis dan berat hasil tangkapan bagan tancap yang menggunakan lampu HPL lebih tinggi dibandingkan dengan lampu TL. Hipotesis penelitian ini adalah hasil tangkapan bagan tancap yang menggunakan lampu HPL lebih tinggi dibandingkan dengan lampu TL.

\section{METODE PENELITIAN}

Penelitian menggunakan metode percobaan. Kegiatannya dibagi dalam tiga tahap, yaitu :

1. Pembuatan lampu HPL yang dilengkapi dengan reflektor dengan sudut bukaan 90;

2. Pengukuran arah sebaran dan iluminasi cahaya 1 unit lampu HPL dengan sudut bukaan $90^{\circ}$ dan lampu tubular lamp 45 Watt (W) merek Cahaya milik nelayan;

3. Ujicoba kedua lampu menggunakan bagan tancap di perairan Sangrawayang,

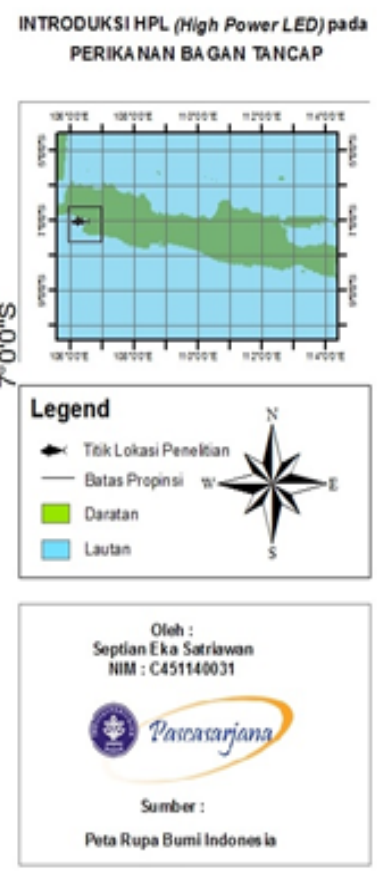


Desa Sangrawayang, Kabupaten Sukabumi, Jawa barat, antara bulan Oktober-November 2016. Peta lokasi penelitian disajikan pada Gambar 1 .

\section{Lampu HPL}

Satu unit lampu HPL terdiri atas reflektor stainless steel berdiameter $32 \mathrm{~cm}$ yang dapat ditutup-kembangkan (Gambar 2a). Sisi bagian dalamnya dilapisi dengan kertas berwarna perak untuk meningkatkan kekuatan pantul cahayanya. Selanjutnya, sebanyak 10 keping HPL $10 \mathrm{~W}$ disusun secara paralel pada bagian tengah reflektor (Gambar 2b dan 2c). Sumber energi lampu berupa baterai kering bertegangan $12 \mathrm{~V}$. Panas yang dihasilkan oleh lampu akan diredam oleh hembusan angin dari kipas yang dipasang pada bagian atas reflektor. Selanjutnya, kipas ditutupi dengan wadah plastik untuk menghindari dari percikan air laut.

Gambar 2d ditunjukkan konstruksi 1 unit lampu HPL yang dilengkapi dengan 2 pipa PVC pada bagian atasnya. Rinciannya adalah satu pipa PVC $\varnothing 3 / 4$ " berfungsi sebagai penyangga dan penghubung antara lampu dengan bagan sepanjang $1 \mathrm{~m}$. Sementara satu pipa PVC $\varnothing 1 / 2 "$ sepanjang $1.2 \mathrm{~m}$ berfungsi sebagai pengatur sudut bukaan reflektor.

\section{Pola sebaran dan iluminasi cahaya lampu pada media udara}

Pola sebaran cahaya dan iluminasi lampu HPL diukur dan dibandingkan dengan lampu milik nelayan. Pengukuran iluminasi menggunakan digital luxmeter model LX1010B (Gambar 3). Konstruksi lampu percobaan menggunakan sudut bukaan reflektor $90^{\circ}$. Adapun, lampu nelayan berupa lampu TL yang dilengkapi dengan penutup seng berdiameter $34 \mathrm{~cm}$ dan tinggi $10 \mathrm{~cm}$.

Pengukuran iluminasi cahaya dilakukan didalam kamar gelap dengan dinding berwarna hitam. Jarak antara lampu dengan luxmeter ditetapkan 1=m
(Gambar 4). Sudut pengukuran dimulai dari $0-360^{\circ}$ dengan selang $\mathrm{a}=10^{\circ}$ (Thenu et al. 2013).

\section{Uji coba lapangan}

Uji coba lampu menggunakan 2 bagan tancap. Masing-masing mengoperasikan lampu TL dan lampu HPL selama 20 hari. Alat peredup lampu berupa regulator digunakan pada lampu HPL. Fungsinya untuk menurunkan tegangan listrik agar cahaya meredup dan ikan semakin mendekati lampu ketika jaring bagan akan diangkat. Kedua bagan tancap dioperasikan secara bersamaan pada kedalaman 9m. Jarak antara bagan tancap sekitar 100m. Prosedur pengoperasiannya mengikuti langkah-langkah sebagai berikut :

1. Lampu digantung di bawah bagan berjarak $1 \mathrm{~m}$ dari permukaan laut;

2. Jaring ditenggelamkan sedalam $8 \mathrm{~m}$ dan lampu dinyalakan selama 2 jam;

3. Jaring diangkat setelah ikan berkumpul di bawah bagan;

4. Ikan yang tertangkap dimasukkan ke dalam keranjang;

5. Lampu dinyalakan dan jaring ditenggelamkan kembali untuk operasi berikutnya;

6. Hasil tangkapan disortir, diidentifikasi dan ditimbang menurut jenisnya di atas bagan.

Data hasil tangkapan berupa berat, jumlah dan jenis organisme tangkapan diplotkan dalam bentuk diagram dan selanjutnya dibandingkan. Jenis uji yang digunakan adalah deskriptif komparatif dan rancangan acak lengkap (RAL) untuk melihat pengaruh perbedaan penggunaan lampu TL dan HPL dengan sudut bukaan reflektor berbeda terhadap hasil tangkapan. Analisis RAL dimulai dengan uji kenormalan menggunakan analisis Kolmogorov-Smirnov dan homogenitas. Jika data menyebar normal, maka data dianalisis dengan uji homogenitas dan rancangan acak lengkap (RAL) (Matjik dan Sumertajaya 2006). 


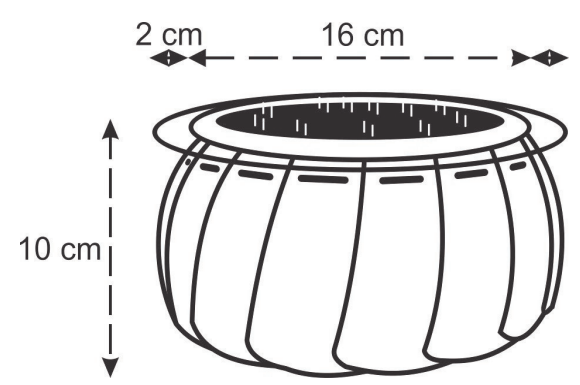

(a) Reflektor tampak samping

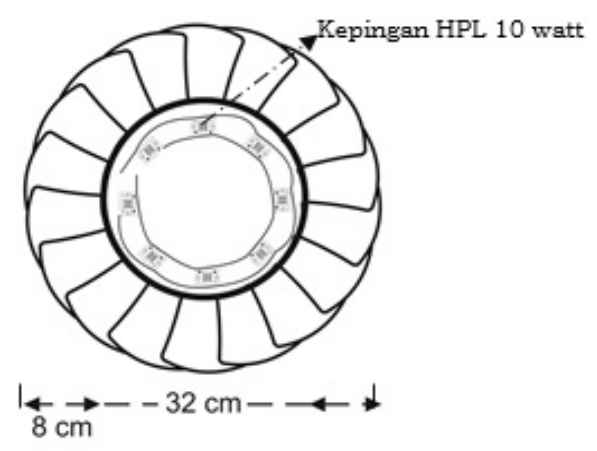

(b) Reflektor dan lampu

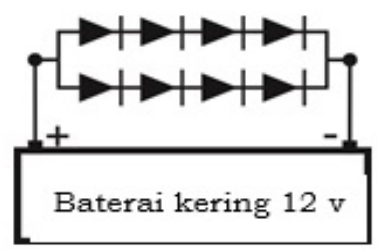

(c) Rangkaian paralel HPL

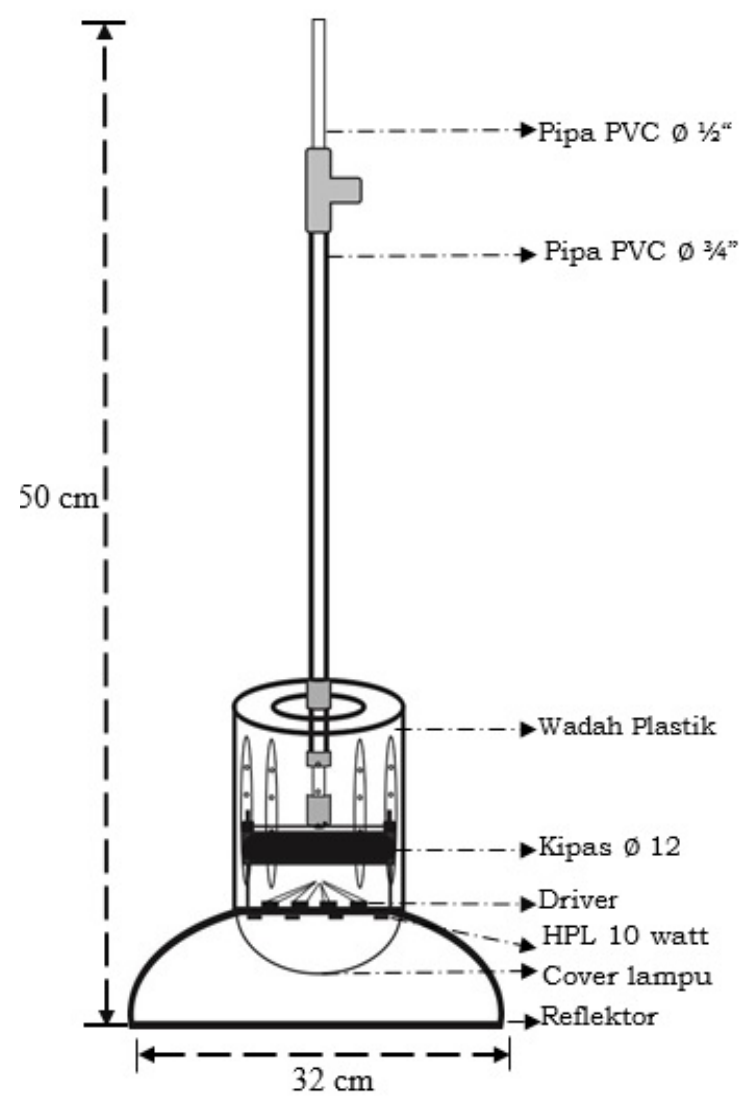

(d) 1 unit lampu HPL

Gambar 2 Lampu HPL
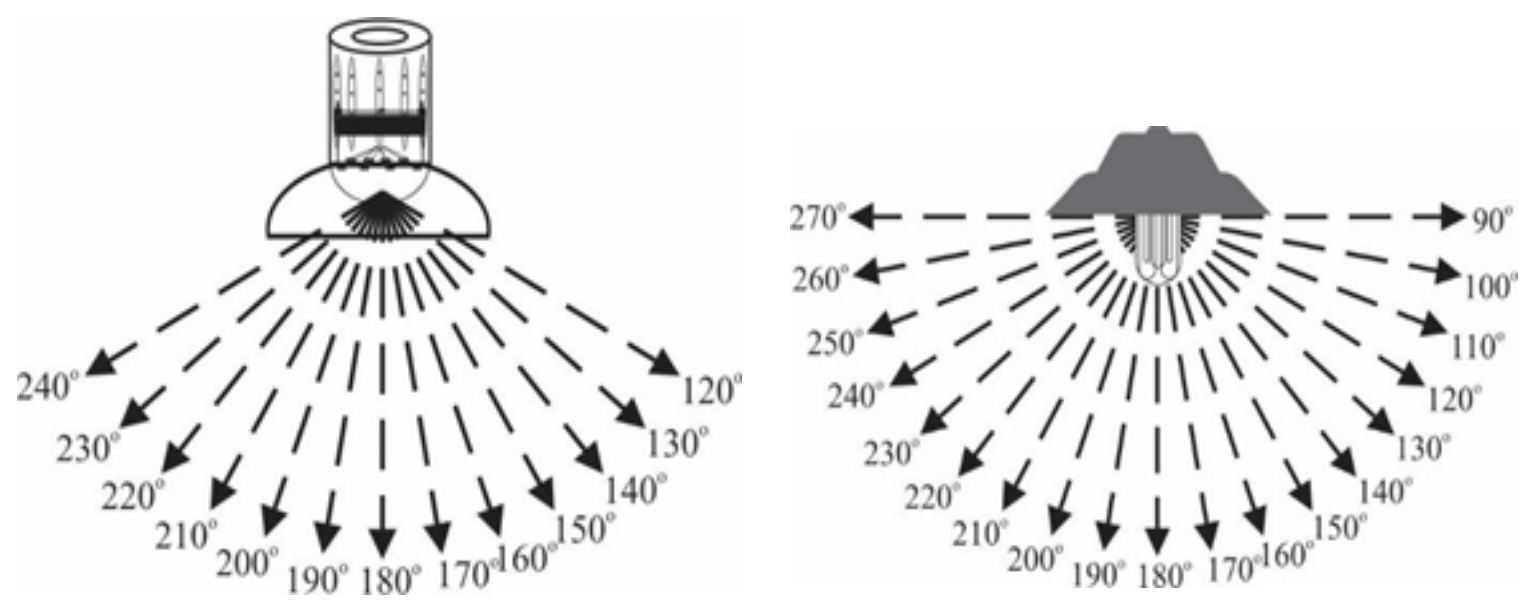

Gambar 3 Ilustrasi pengukuran nilai lux lampu HPL 90 dan lampu TL pada media udara 


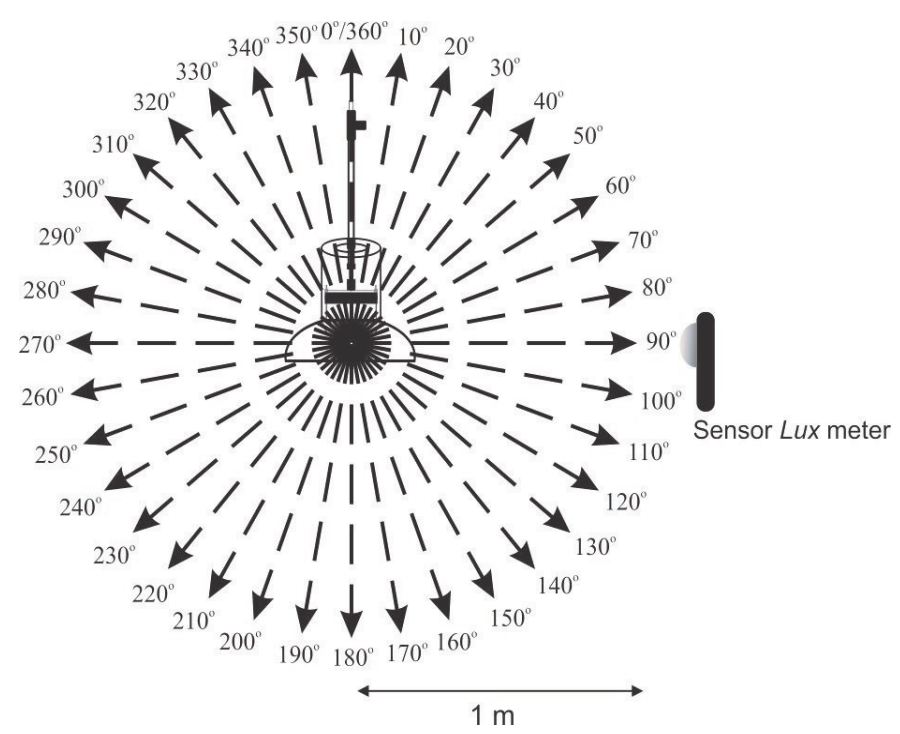

Gambar 4 Ilustrasi posisi luxmeter terhadap lampu pada penentuan pola sebaran dan intesitas cahaya

\section{HASIL DAN PEMBAHASAN}

\section{Pola sebaran dan iluminsi cahaya}

Hasil pengukuran arah sebaran cahaya lampu HPL $90^{\circ}$ dan TL ditunjukkan pada Gambar 5. Kedua jenis lampu menghasilkan arah sebaran berbeda yang dipengaruhi oleh konstruksi reflektor. Lampu HPL $90^{\circ}$ menghasilkan area sebaran cahaya sebesar $120^{\circ}$ yang berada antara sudut $a=120-240^{\circ}$ (Gambar 5a) sedangkan sudut pancaran lampu TL mencapai $300^{\circ}$ $\left(30-330^{\circ}\right)$ ( Gambar 5c).

Konstruksi reflektor mempengaruhi nilai iluminasi setiap lampu. Iluminasi cahaya lampu HPL $90^{\circ}$ terdeteksi pada sudut $a=120-240^{\circ}$ dengan nilai tertingginya 1.358 lux pada sudut $180^{\circ}$. Adapun iluminasi cahaya lampu TL tertinggi sebesar 299 lux $\left(50^{\circ}\right)$. Reflektor pada tudung lampu HPL $90^{\circ}$ dapat memantulkan cahaya lebih tinggi dibandingkan dengan tudung lampu TL. Cahaya yang memancar ke perairan merupakan gabungan atara cahaya langsung dari lampu HPL dan cahaya pantul. Ahmad (2014) menjelaskan penggunaan reflektor menghasilkan iluminasi cahaya yang tinggi. Kertas perak yang digunakan sebagai pelapis dalam pada tudung lampu HPL, menurut Ahmad et al. (2013), akan menambah daya pantul cahaya antara 91-95\%.

Keberhasilan pengumpulan ikan pada catchable area dipengaruhi oleh distribusi cahaya yang dihasilkan oleh lampu (Thenu 2014). Penggunaan tudung seng berwarna putih pada lampu TL untuk memfokuskan cahaya ke bawah bagan belum dapat mengoptimalkan iluminasinya, karena daya pantulnya kecil dan arah pantul tidak terfokus.

\section{Komposisi hasil tangkapan}

Target utama tangkapan bagan tancap berupa ikan pemakan plankton. Odum (1971) menyatakan bahwa plankton hidup pada perairan yang cukup cahaya untuk berfotosintesis dan berkembang biak. Menurutnya, keberadaan plankton akan memikat jenis organisme pemakan plankton untuk mendekati area iluminasi cahaya. Keberadaan ikan-ikan kecil otomatis akan mengundang jenis-jenis ikan predator berkumpul ikut tertangkap oleh bagan.

Hasil tangkapan bagan tancap terdiri atas 14 organisme yang dikelompokkan menjadi dua jenis, yaitu pemakan plankton dan predator. Organisme pemakan plankton terdiri atas 8 jenis, yaitu rebon (Acetes $s p$ ), teri (Stolephorus sp.), tembang (S. Fimbriata), bilis (Thryssa hamiltonii), kembung (Rastrlliger spp.), dan selar (Selaroides $s p$.$) . Berat rebon yang diperoleh mencapai$ $19.858 \mathrm{~g}$ atau $15.99 \%$ dari berat total hasil tangkapan. Nontji (2005) menyatakan habitat udang rebon berada pada pesisir perairan dan muara. Makanan udang rebon adalah zooplankton dan makroalga (Coman et al. 2006). Teri merupakan organisme yang hidupnya bergerombol dan banyak ditemukan di daerah pantai (Carpenter et al. 1997). Jenis teri yang tertangkap berupa teri hitam (Stolephorus buccaneeri) seberat 
2742 g (2.21\%), teri nasi (Stolephorus spp.) $46.120 \mathrm{~g}$ (37.14\%), dan teri paku (Stolephorus indicus) 19.954 g (16.07\%). Gustaman \& Fauziyah (2012) menyatakan ketertarikan teri terhadap cahaya disebabkan oleh keberadaan makanannya yang berupa plankton, udang kecil yang berkumpul di bawah lampu bagan. Tembang merupakan jenis ikan pelagis yang banyak ditemukan di perairan pantai dan hidup secara bergerombol dan berpindahpindah (Nybakken 1992). Bobot tembang yang ditangkap sebesar $4.264 \mathrm{~g}$ (3.43\%). Makanannya terdiri atas fitoplankton dan zooplankton yang didominasi oleh crustacea dan larva molusca (Bleeker 1849). Bilis hidup di perairan pelagis-neritik dengan iklim tropis di kedalaman rata-rata 10-13 m Gray (1835). Jumlah bilis (Thryssa hamiltonit) yang ditangkap sebesar $1.411 \mathrm{~g}$ (1.14\%). Menurut Gray (1835), makananya berupa crustacea dan zooplankton yang disesuaikan dengan mulutnya yang berbentuk inferior. Kembung merupakan ikan pelagis kecil hidup di wilayah dekat pantai dan membentuk gerombolan besar (Syah 2004). Berat kembung yang ditangkap sebesar 396 g $(0.32 \%)$. Menurut Fischer \& Whitehead (1974) makanan kembung berupa plankton. Adapun selar seberat 1.028 g (0.83\%). Selar juga merupakan ikan pelagis kecil yang hidup sampai kedalaman laut $80 \mathrm{~m}$ secara berkelompok dan banyak tertangkap di perairan pantai (Djuhanda dalam Febrianti et al. 2013). Jenis makanannya bervariasi, mulai dari plankton, bentos hingga larva ikan.

Selain menangkap organisme pemakan plankton, bagan tancap juga menangkap jenis-jenis organisme predator yang berburu makanan di atas jaring. Jenisnya terdiri atas cumi-cumi (Loligo sp.), kuwe (Caranx spp.), layur (Trichiurus lepturus), pepetek (Leiognathus sp.), cendro (Tylosurus sp.), dan cawene kuning (Lutjanus mizenkoi). Masingmasing beratnya $3.474 \mathrm{~g}(2.79 \%), 7.957 \mathrm{~g}$ (6.41\%) $10.327 \mathrm{~g}(8.32 \%) 5.590 \mathrm{~g}(4.51 \%)$ $217 \mathrm{~g}(0.17 \%) 854 \mathrm{~g}(0.69 \%)$ dari total tangkapan bagan tancap. Keenam organisme predator tertangkap oleh bagan tancap lebih dikarenakan oleh aktifitas makannya yang berupa organisme pemakan plankton. Detail komposisi berat hasil tangkapan bagan tancap berdasarkan jenis organisme ditunjukan pada Gambar 7. Cumi-cumi ikut tertangkap karena hidup di daerah pantai dan paparan benua sampai kedalaman 400 m (Roper et al. 1984). Layur termasuk jenis ikan karnivor yang dilengkapi dengan gigi yang kuat dan tajam pada kedua rahangnya. Layur tersebar luas pada semua perairan, makanannya berupa udang-udangan, cumicumi, dan ikan kecil berupa teri maupun sardin (Bal \& Rao 1984). Kuwe merupakan ikan pelagis yang hidup di perairan trumbu saat memijah, saat remaja kuwe hidup pada muara dan saat dewasa berada pada laguna menuju laut yang lebih dangkal. Demikian juga dengan pepetek yang berada di perairan pantai dengan kedalaman berkisar 3-10 m (Nontji 2005 dalam taftazani 2003). Cendro merupakan ikan pelagis hidupnya soliter dan dalam kelompok kecil, makananya ikan kecil (Péron \& Lesueur 1821) sedangkan ikan cawene kuning hidup di daerah terumbu atau perairan dangkal (Pertiwi 2011).

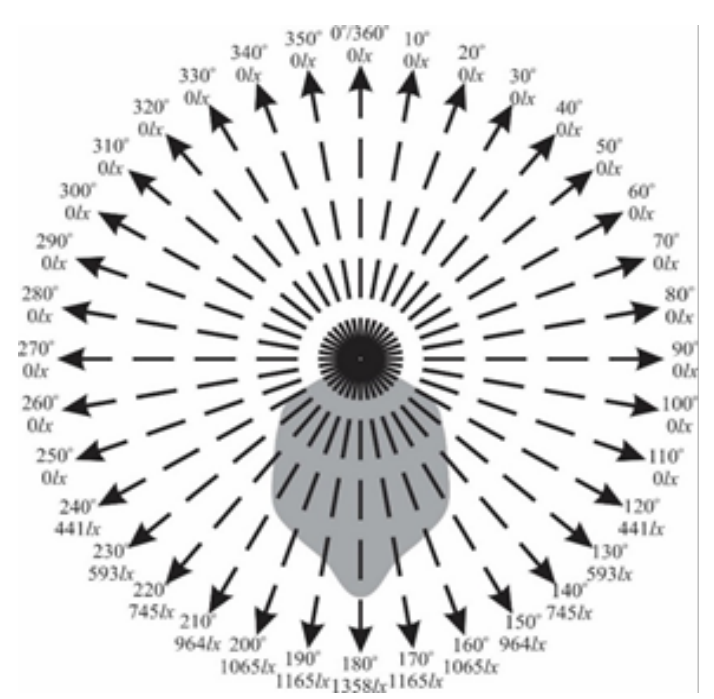

(a) Lampu HPL $90^{\circ}$

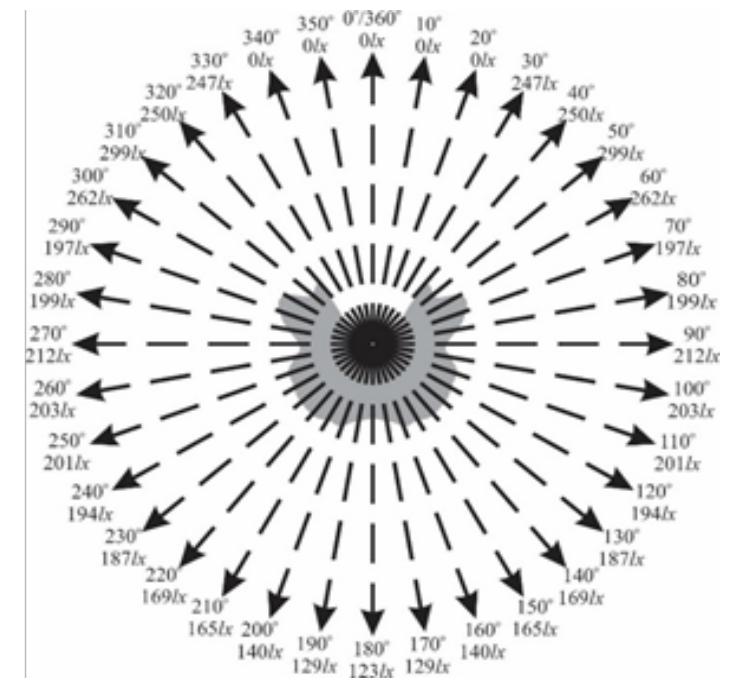

(b) Lampu TL

Gambar 5 Pola sebaran dan iluminasi cahaya lampu lampu HPL 90 dan lampu TL pada media udara 


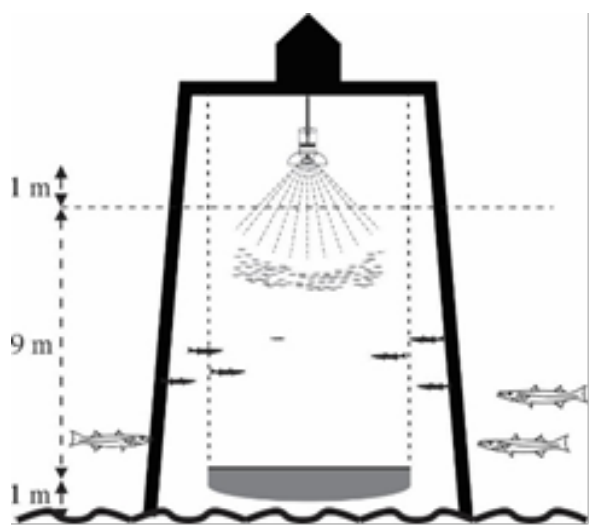

(a) Lampu HPL $90^{\circ}$

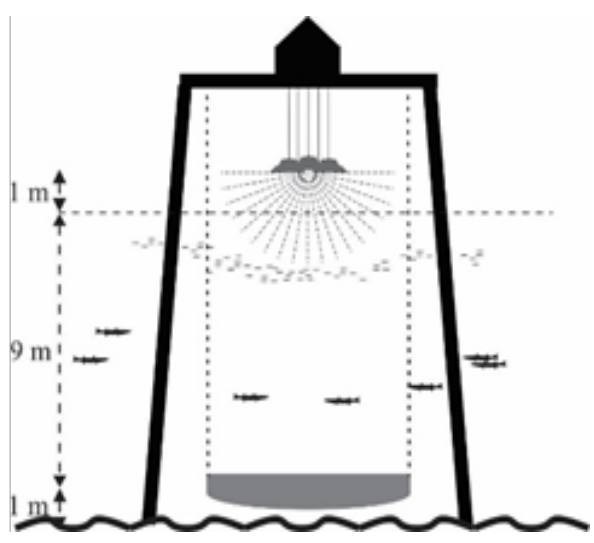

(b) Lampu TL

Gambar 6 Lampu HPL dan lampu TL yang di uji coba pada bagan tancap

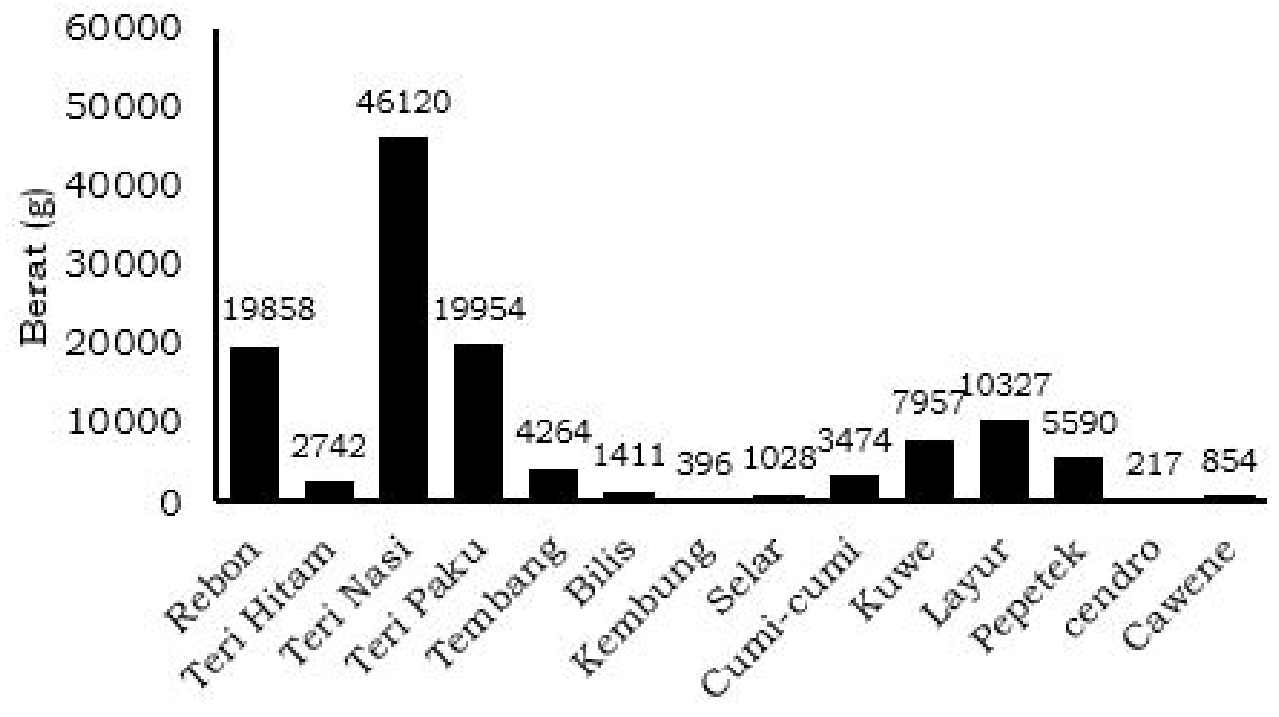

Jenis Organisme

Gambar 7 Komposisi jenis dan berat hasil tangkapan total bagan tancap selama penelitian

\section{Komposisi hasil tangkapan berdasarkan jenis lampu}

Hasil uji kenormalan KolomogrovSmirnov dan uji homogenitas terhadap hasil tangkapan bagan tancap menunjukkan data hasil tangkapan menyebar normal dan bersifat homogen. Perhitungan lanjutan dengan uji statistik parametrik ANOVA RAL memperoleh Fhitung $>$ Ftabel $(6.240>4.091)$ pada $a=0.05$. Ini berarti Ho ditolak. Jumlah hasil tangkapan bagan tancap berbeda nyata. Berdasarkan hasil perhitungan ini, lampu HPL dengan sudut bukaan reflektor $90^{\circ}$ akan meningkatkan hasil tangkapan bagan tancap.

Komposisi jenis dan berat hasil tangkapan bagan tancap menggunakan lampu HPL dengan lampu TL cukup berbeda (Gambar 8). Penggunaan lampu HPL menghasilkan 8 jenis organisme pemakan plankton dengan berat $74.599 \mathrm{~g}$ dan 6 organisme predator $(22.764 \mathrm{~g})$. Lampu TL hanya menangkap 5 jenis organisme pemakan plankton (21.174 g) dan 4 organisme predator (5.655 g). Jenis organisme hasil tangkapan bagan tancap terbanyak adalah organisme pemakan plankton yang didominasi oleh teri nasi dengan persentase $37.14 \%$ dari total tangkapan. Ini disebabkan operasi penangkapan bagan dilakukan pada musim penangkapan ikan teri, yaitu bulan AprilOktober (Puspito et al. 2015).

Organisme yang terkonsentrasi di bawah lampu HPLlebih banyak dibandingkan lampu TL karena pancaran lampu HPL $90^{\circ}$ 
lebih terpusat. Ini menunjukkan bahwa lampu HPL lebih mampu mengumpulkan organisme pemakan plankton. Berdasarkan gambar 5, nilai iluminasi cahaya pada lampu HPL $90^{\circ}$ jauh lebih tinggi daripada lampu TL. Pola sebaran cahaya lampu HPL $90^{\circ}$ yang mengerucut menyebabkan organisme pemakan plankton terkonsentrasi dibawah bagan dan mampu menarik organisme predator menuju area penangkapan (Gambar 6). Keadaan demikian membuat jumlah organisme yang tertangkap menjadi lebih tinggi. Hal ini sesuai dengan laporan Puspito (2012) yang menyatakan pemusatan cahaya ke arah jaring bagan diperlukan untuk mengumpulkan ikan di atas jaring. Adapun penangkapan ikan dengan lampu TL lebih sulit dilakukan karena cahaya yang dihasilkannya menyebar, sehingga organisme pemakan plankton tidak berkumpul di bawah bagan dan organisme predator tidak masuk ke area penangkapan. Puspito (2006) menyebutkan pancaran cahaya yang mengarah ke samping menyebabkan keberadaan jenis-jenis ikan pemakan plankton menyebar di bawah dan di sekitar bagan.

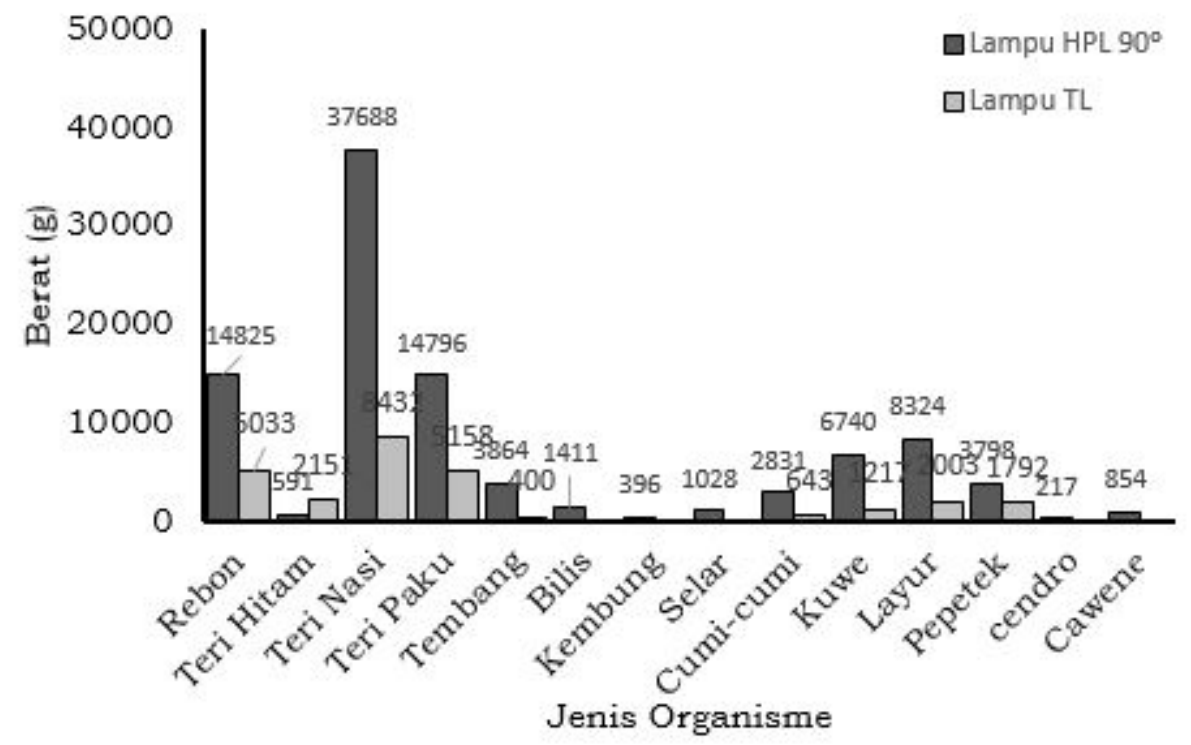

Gambar 8 Komposisi jenis dan berat hasil tangkapan bagan tancap menggunakan lampu HPL $90^{\circ}$ dan lampu TL

\section{Keunggulan menggunakan lampu HPL}

Satu unit lampu HPL berisi 10 keping HPL yang dirangkai paralel dengan daya listrik sebesar $100 \mathrm{~W}$. Lampu ini menggunakan baterai kering sebagai sumber listriknya. Baterai kering memiliki dimensi $20 \times 15 \times 15(p \times 1 \times t)$ dengan berat $15 \mathrm{~kg}$ sehingga mudah dibawa ke bagan tancap. Baterai kering mudah diisi ulang dengan adaptor $10 \mathrm{~A}$ selama 8 jam agar bisa dipakai kembali. Harga pengisian baterai kering menggunakan listrik rumah 1300 VA untuk penggunaan setiap trip penangkapan adalah 725 rupiah. Arus yang dialirkan pada lampu HPL adalah arus DC atau arus searah sehingga aman saat digunakan. Uji daya tahan 1 unit lampu menggunakan baterai kering 70 Ampere (A) $12 \mathrm{~V}$ dapat menyalakan lampu selama 15 jam. Lampu HPL mengalami penurunan nilai lux pada setiap jamnya, namun tidak signifikan. Uji daya ini membuktikan bahwa lampu HPL dapat dioperasikan sempurna pada bagan tancap meskipun hanya menggunakan baterai kering sehingga lampu ini jauh lebih hemat energi dibandingkan dengan lampu TL milik nelayan yang menghabisakan daya listrik lebih besar.

Nelayan bagan tancap menggunakan 5-10 lampu TL dalam setiap operasi penangkapan. Setiap lampu tersebut membutuhkan daya sebesar $45 \mathrm{~W}$ dengan tegangan $220 \mathrm{~V}$. Lampu TL menggunakan arus AC untuk menghidupkanya sehingga dibutuhkan genset sebagai pembangkit listriknya. Penggunaan listrik AC yang berasal dari generator cukup berbahya, karena menggunakan arus bolak-balik. Hal ini membuat nelayan dapat beresiko tersetrum saat mengoperasikanya. Satu kali operasi penangkapan, generator yang digunakan membutuhkan bensin sebanyak 8 liter dengan harga 10 ribu per liter. 
Jadi dalam operasi penangkapan nelayan membutuhkan biaya 80 ribu rupiah, berbeda dengan menggunakan baterai kering 70 A yang menghabisakan 725 rupiah untuk 1 kali operasi penangkapan atau 110.34 kali lipat lebih murah. Generator memiliki dimensi yang lebih besar dari baterai kering yaitu $40 \times 30 \times 25(\mathrm{p} \times 1 \times \mathrm{t})(\mathrm{cm})$ dengan berat mencapai $29 \mathrm{~kg}$ lebih besar dan berat dibandingkan dengan baterai kering 70 A. Hal ini menyulitan nelayan untuk mengangkut genset menuju bagan tancap.

\section{KESIMPULAN DAN SARAN}

\section{Kesimpulan}

Pengoperasian bagan tancap menggunakan lampu HPL menghasilkan 14 jenis organisme dengan berat total $97.363 \mathrm{~g}$, atau lebih tinggi dbandingkan dengan lampu TL yang menghasilkan 9 organisme (26.829 g). Ini membuktikan bahwa hasil tangkapan bagan tancap yang menggunakan lampu HPL $90^{\circ}$ lebih tinggi dibandingkan dengan lampu TL.

\section{Saran}

Lampu HPL perlu di uji cobakan pada alat tangkap lain yang menggunakan alat bantu cahaya antara lain bagan apung dan purse seine. Nelayan Sangrawayang sebaiknya beralih menggunakan lampu HPL untuk pengoperasian bagan tancap, karena hasil tangkapannya lebih berat dan beragam.

\section{DAFTAR PUSTAKA}

Ahmad S, Puspito G, Sondita MFA, Yusfiandayani R. 2013. Penguatan Cahaya pada Bagan Menggunakan Reflektor Kerucut Sebagai Upaya Meningkatkan Hasil Tangkapan CumiCumi. Marine Fisheries. 4(2): 163-173.

Ahmad S. 2014. Penggunaan Reflektor dengan Sudut Berbeda: Upaya Meningkatkan Hasil Tangkapan Bagan di Teluk Kao, Halmahera Utara.

Bal DV, Rao KV. 1984. Marine Fisheries. New Delhi: McGraw Hill Publishing Company.

Bleeker. 1849. Sardinella gibbosa. Fishbase. [terhubung berkala]. [diunduh 2017 Apr 3]. Tersedia pada: http://www. fishbase.org/summary/Sardinellagibbosa.html.

Carpenter KE, Krupp F, Jones DA, Zajonz
U. 1997. Living marine resources of Kuwait, eastern Saudi Arabia, Bahrain, Qatar, and the United Arab Emirates. FAO species identification field guide for fishery purposes. [terhubung berkala]. $293 \mathrm{hlm}$. [diunduh 2017 Apr 3]. Tersedia pada: http://www. fishbase.org/summary/569. Rome.

Coman FE, Connolly RM, Bunn SE, Preston N P. 2006. Food sources of the sergestid crustacean, Acetes sibogae, in shrimp ponds. Aquaculture. 259: 222-233.

Febrianti A, Efrizal T, Zulfikar A. 2013. Kajian Kondisi Ikan Selar (Selaroides Leptolepis) Berdasarkan Hubungan Panjang Berat dan Faktor Kondisi di Laut Natuna yang didaratkan di Tempat Pendaratan Ikan Pelantar Kud Tanjungpinang. Program studi manajemen sumber daya perairan. Fakultas Perikanan dan Kelautan. Universitas Maritim Haji Raja Ali.

Fischer W, Whitehead PJP. 1974. FAO Species Identification Sheet for Fishery Purpose. Eastern Indian Ocean and Western Central Pacific Identification Sheet, Taxonomy, Geographic Distribution Fisheries Vernacular Names. Rome.

Gustaman G, Fauziyah. 2012. Efektifitas Perbedaan Warna Cahaya Lampu terhadap Hasil Tangkapan Bagan Tancap di Perairan Sungsang Sumatera Selatan. Maspari Jurnal 4(1): 92-102.

Gray. 1835. Thryssa hamiltonii. Fishbase. [terhubung berkala]. [diunduh 2017 Apr 3]. Tersedia pada: http://www. fishbase.org/summary/Speciessummary. php?id=589.html.

Mahayanti D. 2004. Analisis tingkat efisiensi daya dan biaya penggunaan lampu neon sistem elektronik terhadap neon sistem trafo berdasarkan desain eksperimen faktorial. Surakarta (ID): Universitas Sebelas Maret.

Matjik AS, Sumertajaya M. 2006. Perancangan Percobaan (dengan Aplikasi SAS dan Minitab). Bogor (ID): IPB Pr. hlm 98-178.

Nontji A. 2005. Laut Nusantara. Jakarta: Penerbit Djambatan.

Nybakken JW. 1992. Biologi Laut : Suatu Pendekatan Ekologis. Alih bahasa oleh HM Eidman, Koesoebiono, DG Bengen, M Hutomo dan S Sokardjo. Jakarta: PT. Gramedia Pustaka Utama.

Odum EP. 1971. Fundamentals of Ecology. W.B. Sounders Company Ltd. 
Philadelphia.

Péron, Lesueur. 1821. Tylosurus crocodilus. Fishbase. [terhubung berkala]. [diunduh 2017 Apr 2]. Tersedia pada: http://www.fishbase.org/summary/977.

Pertiwi W. 2011. Komposisi Jenis dan Ukuran Ikan yang Tertangkap dengan Sero dan Pukat Pantai di Perairan Kota Palopo, Provinsi Sulawesi Selatan. Universitas Hasanudin (ID): Universitas Hasanuddin Makassar.

Puspito G. 2006. Kajian teoritis dalam merancang tudung petromaks. Jurnal mangrove \& Pesisir PSPK, 6(3): 1-9.

Puspito G. 2012. Pengaruh Pemusatan Cahaya Terhadap Efektivitas Bagan. IJFST, 7(2): 5-9

Puspito G, Thenu EM, Julian D, Tallo I. 2015. Utilization of light-emitting diode lamp on lift net fishery. AACCL Bioflux. 8(2): 159-167.

Roper CFC, Sweenwy MJ, Nauen CE. 1984. Cephalopods of the World : An Anotated and Illustrated Catalogue of Spesies of Interest to Fisheries. FAO
Spesies Catalogue Vol. 3. FAO Fish. Synop. Vol. 3.

Syah US. 2004. Kajian Perkembangan Produksi Histamin Selama Penanganan Bahan, Pengolaan dan Penyimpanan Peda Ikan Kembung (Rastrelliger spp.) [Tesis]. Bogor (ID): Fakultas Pascasarjana, Institut Pertanian Bogor.

Taftazani AM. 2003. Uji Performansi Alat Pengering Tipe Efek Rumah Kaca Berenergi Hybrid pada Pengeringan Ikan Pepetek (Lelognathus equulus). [Skripsi]. Bogor (ID): Fakultas Teknologi Pertanian, Institut Pertanian Bogor.

Thenu EM, Puspito G, Martasuganda S. 2013. Penggunaan Light Emitting Diode pada Lampu Celup Bagan. Marine Fisheries 4 (2): 141-151.

Thenu E M. 2014. Aplikasi Lampu Led (Light Emitting Diode) pada Pengoperasian Bagan Tancap [Tesis]. Bogor (ID): Fakultas Pascasarjana, Institut Pertanian Bogor. 